\title{
Studies impacting the clinical world in the European Child and Adolescent Psychiatry
}

\author{
Luis Augusto Rohde
}

Published online: 11 October 2012

(c) Springer-Verlag Berlin Heidelberg 2012

One of the most promising areas in medicine is the so called personalized medicine where pharmacogenetic approach has a clear role [4]. However, the developments in the pharmacogenetic field of psychiatric disorders have not been as quick as in other areas of medicine. This scenario is even slower for child and adolescents mental disorders. In this issue of the journal, Blazquez et al. [1] present an extensive review of the literature describing how certain genes are involved in the pharmacodynamics and pharmacokinetics of fluoxetine in children and adolescents. Initial exciting findings seem to suggest a potential role for polymorphisms in several genes like SLC6A4, HTR1A and MAO-A as moderators of response to fluoxetine in depression. Nevertheless, the authors clearly document the scarcity of studies and the diversity of methodology in the investigations hampering any chance of a major step in defining a more personalized treatment for this disorder at the present moment.

Other relevant research areas in child mental health with impact on clinical work are: (1) the role of environmental factors in child mental disorders, specially smoking during pregnancy in ADHD; and (2) the need of developing friendly non-pharmacological interventions that can help individuals with mental disorders dealing with the impact of symptoms in their daily lives.

There is an unresolved debate in the literature on the real role of smoking during pregnancy in the etiology of ADHD with several authors suggesting that the association found might be solely a product of not controlled confounding variables like the genetic predisposition for ADHD (see

L. A. Rohde $(\square)$

Department of Psychiatry, Federal University

of Rio Grande do Sul, Porto Alegre, Brazil

e-mail: 1rohde@terra.com.br
Motlagh et al. [6] and Thapar et al. [7]). In this issue of the journal, Ellis et al. [5] add interesting findings for this discussion. In a community sample of 995 4-year olds from Norway, they found increased odds for both ADHD and ODD in offspring of mothers that smoked during pregnancy, even after adjusting for potential confounding variables by using the propensity score. Obviously, if a real association exists between smoking during pregnancy and externalizing disorders in children, the implications for public mental health are enormous.

Developmental psychopathology has emphasized the intimate relation between child and adult mental disorders. Pharmacological interventions are key tools for treating core symptoms of some mental disorders like ADHD [2]. However, clinicians are left without many evidence-based options for helping their patients to deal with increasing environmental demands, even more when they grow up entering adulthood. Thus, there is a clear need to test potential interventions in the real world addressing this shortcoming. In this context, Wentz et al. [9] applied a user-centered design to develop a model for internet-based support and coaching for adolescents and adults with ADHD and ASD. The intervention is a mix of support sessions via internet (chat) and two additional in-person meetings. It was designed to last 8 weeks and the model was validated in a pilot study with ten individuals with ASD and/or ADHD. Since quality of life seems to be seriously impaired by ADHD (see Danckaerts et al. [3]), one reassuring finding was an improvement in subjective quality of life at follow-up. Although replication is needed before any firm conclusion on the efficacy of the intervention might be defined, the field certainly welcomes this kind of initiatives.

Finally, but yet in the context of developmental psychopathology, roads from certain temperamental aspects 
during early childhood to child and adolescent mental disorders are well established. One of the most paved is the link between behavior inhibition (BI) during pre-school years and anxiety disorders in school-age children. However, clinicians wanting to monitor behavior inhibition early in life have always faced the shortage of valid instruments applicable in multi-ethnic population. Vreeke et al. [8] describe the process of testing the reliability and some aspects of validity for a promising instrument to assess this construct in a paper in this issue of the journal. The psychometric properties of the Behavioral Inhibition Questionnaire-Short Form (BIQ-SF) were evaluated in a huge multi-ethnic sample of 2,343 Dutch pre-scholars. The robust properties found suggest that this instrument might be valuable for a quick assessment of BI in the real world.

Conflict of interest Dr Luis Augusto Rohde was on the speakers' bureau and/or acted as consultant for Eli-Lilly, Janssen-Cilag, Novartis and Shire in the last 3 years (less than US $\$ 10,000$ per year and reflecting less than $5 \%$ of his gross income per year). He also received travel support (air tickets and hotel) for attending two Child Psychiatric Meetings from Novartis and Janssen-Cilag in 2010. The ADHD and Juvenile Bipolar Disorder Outpatient Programs chaired by him received unrestricted educational and research support from the following pharmaceutical companies in the last three years: Abbott, Eli-Lilly, Janssen-Cilag, Novartis, and Shire. He also receives research support from Brazilian government institutions (CNPQ, FAPERGS, HCPA and CAPES) and royalties from Oxford Press and ArtMed.

\section{References}

1. Blazquez et al (2012) Fluoxetine pharmacogenetics in child and adult populations. Eur Child Adolesc Psychiatry. doi:10.1007/ s00787-012-0305-6
2. Buitelaar J, Medori R (2010) Treating attention-deficit/hyperactivity disorder beyond symptom control alone in children and adolescents: a review of the potential benefits of long-acting stimulants. Eur Child Adolesc Psychiatry 19(4):325-340

3. Danckaerts M, Sonuga-Barke EJ, Banaschewski T, Buitelaar J, Dopfner M, Hollis C, Santosh P, Rothenberger A, Sergeant J, Steinhausen HC, Taylor E, Zuddas A, Coghill D (2010) The quality of life of children with attention deficit/hyperactivity disorder: a systematic review. Eur Child Adolesc Psychiatry 19(2):83-105

4. Di Francia R, Valente D, Catapano O, Rupolo M, Tirelli U, Berretta M (2012) Knowledge and skills needs for health professions about pharmacogenomics testing field. Eur Rev Med Pharmacol Sci 16(6):781-788

5. Ellis et al (2012) Smoking during pregnancy and psychiatric disorders in preschoolers. Eur Child Adolesc Psychiatry. doi: 10.1007/s00787-012-0300-y

6. Motlagh MG, Katsovich L, Thompson N, Lin H, Kim YS, Scahill L, Lombroso PJ, King RA, Peterson BS, Leckman JF (2010) Severe psychosocial stress and heavy cigarette smoking during pregnancy: an examination of the pre- and perinatal risk factors associated with ADHD and Tourette syndrome. Eur Child Adolesc Psychiatry 19(10):755-764

7. Thapar A, Cooper M, Eyre O, Langley K (2012) Practitioner review: what have we learnt about the causes of ADHD? J Child Psychol Psychiatry. doi:10.1111/j.1469-7610.2012.02611.x (Epub ahead of print)

8. Vreeke et al (2012) The assessment of an inhibited, anxiety-prone temperament in a Dutch multi-ethnic population of preschool children. Eur Child Adolesc Psychiatry. doi:10.1007/s00787012-0299-0

9. Wentz et al (2012) Development of an internet-based support and coaching model for adolescents and young adults with ADHD and autism spectrum disorders: a pilot study. Eur Child Adolesc Psychiatry. doi:10.1007/s00787-012-0297-2 